\title{
Tanzanian Controversy on Resources Endowments and Poverty
}

\author{
Msafiri Yusuph Mkonda ${ }^{1,2, *}$, Xinhua He ${ }^{1,3}$ \\ ${ }^{1}$ Centre of Excellence for Soil Biology, College of Resources and Environment, Southwest University, China \\ ${ }^{2}$ Department of Physical Sciences, Faculty of Science, Sokoine University of Agriculture, Tanzania \\ ${ }^{3}$ School of Plant Biology, University of Western Australia, Australia
}

Copyright $\mathrm{C} 2017$ by authors, all rights reserved. Authors agree that this article remains permanently open access under the terms of the Creative Commons Attribution License 4.0 International License

\begin{abstract}
This paper examines the existing resources curse in Tanzania with detailed analyses on the controversy. A country with high resources endowments: i.e. about 44 million hectares of arable land, precious minerals, forests resources, water and wildlife but is among the poorest countries in the planet Earth. Here we reviewed over 25 reports, journal papers and books and found that all precious natural resources have insignificant contribution to socio-economic development of the people. The resource curse is confirmed in about all resources as there is no correlation between the quality of life and resources endowments. In recent years, the country has recorded the lowest per capita income at $\$ 960$ with weak purchasing power parity. This declares that all consumptions, investments and government spending are insignificant. In addition, approximately $75 \%$ of the population depends on under-developed smallholder primary agricultural production, small-scale mining and other micro economic sector. Under such a situation, about $51 \%$ of the Tanzanians are poor and roughly one-third of these people live in abject poverty. Similarly, despite of the recent discovery of 2.17 trillion cubic feet of natural gas deposit, more than $50 \%$ of households have no access to basic requirements such as electricity, medical care etc. The human development index $(\sqrt[3]{\text { LEI - EI - II. })})=0.521$ (low) i.e. life expectancy has decreased to about 50 years, illiteracy rate is about $68 \%$, high rates of malnutrition and poor access to safe water both in urban and rural areas are other acute problems to the Tanzanians. Food insecurity is about $41 \%$ of households due to poor yields. The major causes for all these misfortunes are poor governance, policy failure, interference of political interest in professionalism, inadequate technology and corruption just to mention a few. Despite of the efforts as stipulated in section 7 of this paper, it is further projected that competition over resources use is expected to elevate being from within and outside the country. This will exacerbate the level of poverty among the poor and increase their vulnerability. To address the problem, the government needs to undertake serious and sustainable measures over the control and use of natural resources.
\end{abstract}

Keywords Extractive Sector, Natural Resources Curse, Poverty, Tanzania, Weak Governance

\section{Introduction}

Are natural resources a curse? It has been evidenced that some less natural resourced countries are economically developing using the little available resources in a sustainable while other countries with plenty endowments are extremely poor [5]. Most of these countries are from Sub-Saharan African countries. Tanzania is among the best endowed countries with diverse natural resources but is among the poorest countries in Africa and the world at large $[2,26]$. Tanzania has mineral deposit of gold, diamond, tanzanite and mica to mention few. It has about 44 million hectares of arable land potential for agriculture, water bodies (ocean, lakes and great rivers) for fishing industry, national parks (with variety of animals and diverse plants species) and natural forest. For the resource it has, the country deserve to be a donor country and not economic dependent as it is [25].

Within the country, the degree of poverty varies spatially, where the poor mainly live in rural areas. At present Tanzanian population that lives in rural areas account to $\sim 80 \%$ of the total population, and $60 \%$ of these rural dwellers are living below the poverty line [25]. In general rural households account for $\sim 90 \%$ of the poor and they depend on small scale agriculture for their subsistence (food and income). In 1991, rural households accounted for $\sim 85 \%$ of the poor with a non-significant improvement to the present time. This ratio rose to more than $90 \%$ in 1993[1]. Meanwhile, current statistics from Poverty and Human Development Report shows that, the incidence poverty distribution in Tanzania particularly in 2007 was $16.4 \%$ for Dar-es-salaam, $24.1 \%$ for other urban areas, $37.6 \%$ rural areas and $33.6 \%$ for Mainland Tanzania implying that the situation is worse in rural areas [25]. It is obviously that the figure has almost remained the same due to weak initiatives 
towards poverty alleviation.

Currently, the country has an approximated population of more than 50 million and is among the countries with the lowest per capita income in the world [2,25]. It has about 960 US\$, which is lower than the average for Sub-Saharan Africa 1000 US\$ $([25,26]$. Agricultural sector is the engine of Tanzanian economy as employs about $90 \%$ of the Tanzanian especially in rural areas. This percent also includes the agro-business industry of Tanzanians. The sector is providing up to $50 \%$ of the Gross National Product (GDP) and $80 \%$ of the exports. However, the sector is doing poorly in terms of output due to number of reasons like poor technology applied, lack of economic incentives such as subsides as well as the negative impacts of climate change $[1,2,3]$.

The current total GDP (2016) $=\mathrm{C}+\mathrm{I}+\mathrm{G}+(\mathrm{X}-\mathrm{M})$ is approximated to be $\$ 46.695$ billion whereas $\mathrm{C}=$ consumption, $\mathrm{I}=$ investment, $\mathrm{G}=$ government spending and $(\mathrm{X}-\mathrm{M})=$ net export $[1,7,25,26]$. According to World Bank $[26]$, the country's human development index $(\sqrt[3]{\mathrm{LEI}-\mathrm{EI}-\mathrm{II} .})=0.521$ (low); that means, the life expectancy, quality of education and per capita income are low as stipulated in different items above. Where LEI $=$ life expectancy index, $\mathrm{EI}=$ education index, and $\mathrm{II}=$ income index. In all these aspect, the country has low figures implying that life expectancy, education standard and per capita income are low $[21,25,26]$.

On the basis of these premises, this paper has seven major sections in which it has argued that resource curse is active and alive phenomenon. At once time Jean Bodin, the sixteenth-century philosopher and political theorist said "men of a fat and fertile soil are most commonly effeminate and cowards whereas ... a barren country makes men ... careful, vigilant and industrious". Probably his statement is still living.

\section{Location and Endowment of the Study Area}

Tanzania is located on the eastern coast of Africa, south of the equator between latitudes $1^{\circ} 00^{\prime} \mathrm{S}$ and $11^{\circ} 48^{\prime} \mathrm{S}$ and longitudes $29^{\circ} 30^{\prime} \mathrm{E}$ and $39^{\circ} 45^{\prime}$. Eight countries - Kenya and Uganda in the north, Rwanda, Burundi, Democratic Republic of Congo and Zambia in the west, Malawi and the Republic of Mozambique to the south shore boundaries with Tanzania. The eastern side of Tanzania is a coastline of about $800 \mathrm{~km}$ long marking the western side of the Indian Ocean. Tanzania has a total of $945087 \mathrm{~km}^{2}$, and out of this area, water body's cover $61,495 \mathrm{~km}^{2}$ which is equivalent to $6.52 \%$ of the total area. Tanzania has been endowed with diverse natural resource; arable land ( 44 million hectares), forests, fisheries, lakes (Victoria, Tanganyika, Rukwa, Manyara, Natron and Eyasi), Rivers (Rufiji, Ruvuma, Ruaha, Ruvu, Wami and Malagarasi to mention few) National parks (Serengeti, Mikumi, Ruaha, Manyara, Kitulo) to mention few, Game Reserves and nature conservation areas (Selous and Ngorongoro) to mention few. Moreover, Tanzania has diverse geological resources including; minerals such as gold, diamond, tanzanite, mica, iron, coal, gas and oil. Some of these resources are already exploited with little economic significant to Tanzania [23, 24, 25].

We reviewed over 25 literature sources which most of them are government, IMF or World Bank reports. We used these sources because are authentic and trusted. As well, the observation from the site supported the consistency of the study.

\section{Conceptualization of Key Terms}

\subsection{Poverty}

According to Research on Poverty Alleviation; poverty refers to a situation of lack of sufficient means or income for attaining minimum level of living. Moreover, the term explains on the vulnerability to changing economic and natural condition. Krieger, [4] defined poverty as lack or be denied adequate resources to participate meaningful in the society. Poverty is considered multi-faceted phenomena that include vulnerability and powerlessness, deprivation, isolation, lack of decision-making power, lack of asset, loss of endowment, entitlement failure and insecurity [11, 12]. In most cases the poor are sought by headcount as those who fall below a given income/consumption level or 'poverty line' [9]. Different scholars give some criteria on how a person or a country should be called poor.

Despite of the fact that poverty is subject to relativity; generally it is a condition in which a person or community is deprived of, or lacks the essentials for a minimum standard of well-being and life standards. It goes beyond the economic aspect by looking at it in different dimensions for instance inappropriate policies and poor governance (lack of accountability, transparency, participation) leads to wrong or unsatisfactory decision making. Absolute and relative poverty are the dominant types of level of poverty in Tanzania $[11,12]$. The former is based on income poverty while the later one is based on shortage of food poverty and non-income aspects $[14,15]$. In the context of Tanzania about $51 \%$ of the Tanzanians are poor, and then roughly one-third of these people live in abject poverty. About $48 \%$ of households have no basic requirements. Life expectancy has decreased to about 50 years. Illiteracy rate is about $68 \%$, high rates of malnutrition and poor access to safe water both in urban and rural areas are other acute problems to the Tanzanians. Food insecurity is about $41 \%$ of households due to inadequate crops yields [25]. These are some of the basic indicators of poverty in Tanzania.

\subsection{Natural Resources}

Natural resources are naturally occurring substances that are considered valuable in their relatively unmodified form [10]. For example, minerals, oil, fishery, land, hunting blocs, forestry and wild animals are natural resources available in 
Tanzania. A natural resource's value rests in the amount of the material available and the demand for it. Agriculture is determined by its usefulness to production such as the level of technology, policy and governance applied [27]. Natural resources are mostly classified into renewable and non-renewable resources as explained hereunder.

\subsubsection{Renewable Resources}

These are resources, which can be replenished within a comparative short period. They are generally living resources for examples fish, whale, shark, and forests, which can restock (renew) themselves if they are not over-harvested but used in a sustainable way. Once renewable resources are consumed at a rate that exceeds their natural rate of replacement, the standing stock will diminish and eventually run out. The rate of sustainable utilization of a renewable resource gives chance the restocking of that particular resource. Forest is a good example of this type of resource. They can be regenerated, replenished, re-made, re-grown or regenerated [25].

\subsubsection{Non-Renewable Resources}

These are resource that exists in a fixed amount and they cannot be regenerated, replenished, re-made, re-grown or regenerated within the human being life span, they take long time (millions of years) to replenish [2, 22, 23]. A good example is mineral (gold, tanzanite and diamond) and fossil fuel. In other way, resources can be classified based on their origin as biotic and biotic. Biotic resources are derived from living organisms such as forest. On other side, abiotic resources are derived from the non-living world such as land, water, mineral, and air [18].

\section{The Status of Poverty in Tanzania}

Tanzania is among the poorest countries in Sub-Saharan whose budget is still largely dependent to foreign donors [2, 26]. The trend of dependency shows that there is still a long way to reach independent budget. The United Nations report on human development published early in 2008 mentioned Tanzania as one of the poorest nations in the world by placing it at 47 positions out of 50 poor nations in the world $[22,23,25]$.

Under normal circumstances, it is hard to accept this truth because of the endowment level of natural resources in the planet like gold, tanzanite, diamond and other valuable raw materials. Based on a composite measure of deprivation in food security, income and production, education, health services and nutritional status in 1997, the poorest region was Dodoma followed by Kagera and Lindi. The most well off regions were Dar-es -Salaam followed by Ruvuma and Kilimanjaro [16, 17, 18, 19, 25].

From the period of independence up to recent years (19602010) the per capita income of Tanzanians has been increasing slightly [10]. Over the period real income collected for inflation rose by $22 \%$, which is less than $0.5 \%$ per annum. Connecting 1960 and 1976 there was an average income growth of about $2 \%$ per annum. However, from that period onwards the country experienced a serious decline occurred and by the mid-1980's incomes were back at the 1967 level $[8,9,10]$. Despite some recent improvements, per capita income in 2010 averaged US\$280 and currently has increased to about US\$362.

Nevertheless, the report by [21, 22, 23] shows that, the ratio of the population below the food poverty line has declined from $38.6 \%$ to about $30.3 \%$ (decline of $8 \%$ ) over the same period. In addition, more than one third of Tanzanians cannot satisfy their basic needs [25]. Furthermore $\sim 53 \%$ of the rural population has no access to protected water while only $10 \%$ of the Tanzanians have access to electricity whereas the rest $90 \%$ do not access electricity. This means that majority Tanzania cannot easily access information from media devices which uses electricity. Despite the fact that agriculture is a backbone of Tanzanian economy, the sector has no economic significance as $\sim 95 \%$ of the food grown is traditionally based and rain-fed. Different programmes' and initiatives have been established with little outcome. Currently the country has the "Kilimo Kwanza" (Agriculture first in English). This initiative aimed at spearheading the development of agricultural sector. Its vision is to transform subsistence to commercial agriculture seeking to achieve (GR) Green Revolution in Agriculture [25]. However, the hope of the programme to meet its objective is in great doubt.

\section{Potential Roles of Natural Resources to Tanzania Economy}

Natural resources have significance contribution to make if are properly utilized $[22,23,24]$. The guiding principle in this aspect is that any project, strategies and plans using natural resources should be economic viable, environmentally sustainable and social welfare [2]. Basing on this idea hereunder are some of the economic potentials of using natural resources and their contribution to Gross Domestic Product (GDP).

\subsection{Agriculture}

Agriculture is "the back-bone" of Tanzanian economy and it accounts for about $45 \%$ of Gross Domestic Product (GDP), $60 \%$ of export earnings and $80 \%$ of the population's livelihoods (URT 2002a). Tanzanian agriculture (food crop) is mainly in small scale, subsistence and rain-fed in nature. The increased efficiency in production within the sector has been a key factor of achieving the 6-8\% annual growth rate targeted in the National Strategy for Growth and Reduction of Poverty [25]. The target was to increase from $5 \%$ in 2003 to $10 \%$ in 2010; a target which was not achieved [18]. On other hand, modernization and expansion of agriculture through intensified irrigation (Green Revolution), utilization of pesticides and fertilizers had adverse effects on the environment. The impacts were worse when accompanied by 
poor agronomic practices and therefore lead to water pollution, reduced water flows, deforestation and land degradation [23]. In whole, despite of serving the livelihoods of the majority, the sect has insignificant contribution to economic development.

\subsection{The Mining}

The sector experienced double-digit growth during 2004, but only accounts for about $2 \%$ of total GDP in that year and accounted for 3.5\% of GDP in 2006 [26]. There is some progress because around 1990's the mining industry in Tanzania was still artisanal. Despite of being the Africa's third largest exporter of gold, and produces a number of other valuable minerals for export, Tanzania has not yet exploited the mineral potentials for the benefits of her people [8]. Foreign companies have been in Tanzanian mines for decades but insignificant impacts have been felt to the people via socio-economic services.

\subsection{Tourism Industry}

The country has thousands of elephants, lions, rhinoceros, buffaloes, wild beast, cheetah, leopards and antelopes to mention few. Then, the country has Mount Kilimanjaro the highest mountain in Africa, The Serengeti National Park with about every terrestrial wild animal found on the earth [25]. Despite of the annual increase in number of tourists, still the country had a long way to make it perfect. The trend show that the sector has grown at an average rate of $\sim 6 \%$ from 2004 to 2012 contributing to $~ 5 \%$ of GDP.

\subsection{Wildlife}

This sector has a great potential for increased growth and revenue generation in the country, and is important for the food security, nutrition and income of rural communities. Nevertheless, the sector suffers from mismanagement, underpricing, and over-use of resources, loss of revenues and limited sharing and participation of rural communities. If well managed, the game-hunting industry is one of the few non-farm industries with potential for economic development in remote rural areas of Tanzania $[2,3,4,5]$.

According to the follow-up regulations to the Wildlife Act (from 1998) local communities should receive at least $20 \%$ of hunting revenues, but this has not been in implemented. About two-thirds of the population eats wild meat and $\sim 95 \%$ of the rural population claim wild meat to be their most important source of protein. The findings about the value of wildlife in Tanzania include $\sim 38 \%$ of Tanzanian land is under some form of protection and tourist hunting generates $\sim 27$ million gross per annum [6]. In addition, tourist hunting earns the Wildlife Division $\$ 10$ million per annum, buffalo yield the most trophy fee, followed by leopard and lion. On other hand, it is estimated that 200 people are killed by wildlife each year. This kind of interaction between man and animal is not healthier.

\subsection{Tanzanian Forests and Woodland}

Tanzanian forest and woodlands covers $\sim 30 \%$ of the total land area and support the livelihood of about $\sim 80 \%$ of the poor rural population who use it a source of energy and building materials. Specifically, it provide goods and services of crucial importance to poor households and the national economy $95 \%$ of the energy supply, $75 \%$ of the construction materials and almost all indigenous medicinal products are estimated to be directly derived from forest biodiversity [18]. In addition, eco-system services, such as soil conservation, watershed protection and carbon sequestration, have a large indirect economic value $[6,19$, 20].

Recent estimates that includes the illegal use of forest products shows that the sector contribution can be as high as $10 \%-15 \%$ of the GDP, but currently its contribution is estimated to be $5 \%-10 \%$ only. The magnitude of the problem is attributed by poor governance especially in local government authorities. The log scam of 2004 on coastal districts was one of the major crises in the sector $[6,19,25]$.

\subsection{Fisheries}

Tanzanian fisheries industry represents a significant source of revenue and foreign exchange. It sustains people's livelihoods in the form of food security, employment and income of poor people. Oceans and inland drainage are sources of fishery industry. Inland fisheries from Lake Victoria are overexploited whilst the marine fisheries have growth potentials albeit it faces challenges from dynamite and poisonous fishing. In both the inland and marine fisheries there are conflicting interests between communities reliant on fish resources for their livelihoods and the export oriented commercial fisheries [23].

Tanzania's fisheries export depend much on the lake Victoria Nile Perch where in 2004 the gross export value increased to US\$ 100 million from US\$ 45 Million of 1996. Nile Perch fishery generates a range of employment opportunities including the manufacture of fishing gear and vessels, fish transport and in post-harvest processing [25]. Currently, there are about 12 large-scale commercial fish processing factories operating in the shore of lake Victoria. These industries provide about 28000 jobs as well as market for fish where about US\$ 25000 is spent a day by these industries [10].

\section{Challenges Facing Effective Utilization of Natural Resource}

This section reviews the actual and potential challenges facing the effective utilization of Tanzanian natural resources. This is where Tanzanian has been left behind by other Sub-Saharan African countries. And these challenges relate to social, political, economic, technological and biophysical factors. Here under are these challenges: 


\subsection{Inadequate Technologies}

Technology is a determinant for natural resources management and utilization. Agriculture, forestry, mining or tourism need advanced technology to make smooth progression. Agriculture is a huge industry which employs a large labour force. Tanzanian agriculture is peasantry in nature, use of poor tools (hand hoe), it is rain fed and practiced for subsistence especially in rural areas. In that aspect, it is difficult for agriculture to sustain export expansion near that of 1974 as number of significant technical transformation had taken place within the sector $[21,22,23]$.

Growth in Agricultural sector had taken place since 1960's and 1970's as result of expansion of cultivated land rather than introduction of intensive agriculture. In 1974 export volume fell by $35 \%$ while in 1980 the volume of exports was equivalent to only $43 \%$ and the trade gap was (Tanzania shilling) Tsh. 6 billion [14, 15]. In mining, forestry and wildlife; advanced technology is needed to transform artisanal mining, small holder farming and poaching to large scale mining, commercial agriculture and permitted hunting respectively.

\subsection{Weak Governance}

Good governance is explicit to transparency, participatory, accountability and good decision making. About $90 \%$ of the district councils have no good governance. Poor governance distorts the good planning and implementation of different plans for national development. Weak government comes in the form of corruption, lack of transparency, weak accountability and participation of the local communities [25]. According to Afrobarometer survey held in 2008, the respondents said that, local councilors were involved in corruption than in the previous years. And these counselors are involved in decision making in local level thus if are corrupt, they cannot make use of resources. In general; the accountability, openness and accountability over natural resources management and use is insignificant.

\subsection{Corruption}

Corruption is one of the great rivals that impact the Tanzanian development [27]. Corruption leads to unsustainable exploitation of natural resources for the development of the country [25]. Corruption affects tax collection system, legal contracts, provision of permits and areas related to socio-economic aspects. Corruption has affected smooth operation of a number of production industries, which are claimed to pollute the environment in the country [5].

Through corruption, unfaithful government leaders acquire a $10 \%$ royalty from foreign investment, mineral companies, hunting blocks, polluting industries, fishery and harvesting endangered forest species. In addition, they forge some permits to allow illegal use of resources at the expense of corruption. This is a more acute issue in mining sector where the percentage gained by the country in the production is too small (3\% royalty) implying that $\sim 97 \%$ is gained by foreign investors, and thus going to benefit their countries [25].

\subsection{Poor Participation in Natural Resources Use/Access}

Because of weak governance, there is no full participation of marginalized groups in natural resources management and utilization. There are lot of restriction instead of building community's capacities and involving them in the resources management. Women, pastoralists and other marginalized communities have no say in the process of decision making and their concerns are not taken into account. It is at very few instances where farmers and marginal user groups are least considered in land allocation and land use planning at village level. For example in Loiborsoit village in Simanjiro district in Arusha, over 9,000 ha of grazing land was allocated to farmers for agricultural purposes after being a pasture land for the period of more than 10 years [25].

\subsection{Weak Legal Contracts with Investors}

Despite of having a good number of competent lawyers, Tanzania is doing unsuccessfully in setting contracts with the investors. This has been more critical in mining sector where the investors earn a lot while the country remains poor with only $3 \%$ revenue in that production [25]. However, this scenario is highly accompanied with corruption as the people with authority are bribed for their private gain at the expense of the government. Energy sector is another area where corruption scam is normal cases. Tanzania signed contracts with foreign investors to run energy sector without satisfying itself on the long-term repercussion $[3,4,5]$. Despite of the recently discovery of 2.17 trillion cubic feet of natural gas deposit, insignificant benefits are expected to reflect the situation.

\subsection{Policy and Legal Framework Failure}

Policies give supportive ways for communities on how to manage, develop and make use of available natural resources in the country. Tanzania has a number of policies addressing on how different resources can be managed and used $[17,18,19]$. Some of the dominant policies are that of land, water; forest and wildlife. In the descriptions and directives, these policies fail to address some issues.

Unharmonized policy is among the problems facing natural resources utilization and management. They bring some contractions among them and therefore leading to mismanagement of the natural resources. This situation lays conflicting condition among these different policies and being difficult to run some development projects which subsequently reduces poverty of the country. Environmental policy denies whoever to attempt anthropogenic activities within 60 meters from the water sources while land policy 
allows up to zero distance from water sources. This conflicting directive is one example among others.

\subsection{Insufficient Training, Research and Dissemination of Research Findings}

Despite of the extensive research network which might have been done in Tanzania; research services are not enough to enable and develop appropriate use of available natural resources. Technological packages for farmers are needed for improving their crop yields. Technological models like Decision System Support Agro-technological Transfer (DSSAT) need to be developed and adopted in order to make best use of land and improve crop yields [21, $22,23]$. Likewise, the provision of research services is constrained by disintegration of research system, poor co-ordination, inadequate funding, and lack of priorities and poor research-extension [21]. These shortfalls reduce the efficiency of harnessing and using the resources.

\subsection{Globalization}

The free movement of goods, technology, capital, market and knowledge around the world has significant impact to natural resources management [25]. Globalization in Tanzania comes in 1990s with a lot of illusion, that it was possible for everyone to be self-employed if given the entrepreneurship skills. It guaranteed that free markets could help the transaction of trading activities.

The benefits from trade would trickle down to the poverty but the reality has been different, the number of low-income people has risen [2]. Under globalization there have been pros and cons in it where some investors has gone according to the ambition of the government while others not. In mining, hunting blocks, tourism and forest resources there are investors who have mismanaged the resources for their benefits. For example, there are some trees species which are not allowed to be harvested. In the southern Tanzania (Mtwara and Lindi) there is usually log scams associated with the deforestation of endangered species. Therefore, under free trade and capital, a lot of resources seem to be mismanaged and misallocated.

\subsection{Unequal Balance of Payment}

There is no equal trade balances in the World market as some good from developing countries are sold in low prices as they are graded as poor. Tanzania is among the countries which are affected by this system. Tanzania experienced the fall of her agricultural prices in the world market, which resulted to the decline in national economy and the provision of social services. Macro-economic policy is concerned with ensuring price stability and avoiding debt and balance of payments problems but it may not considers much about the developing countries.

\section{Prospects}

Tanzanian prospects on the best use of resources and alleviating poverty lies on the efforts posed by the government to reducing poverty through sustainable use of natural resources.

\subsection{Efforts Done to Alleviate Poverty}

\subsubsection{Tanzania Development Vision 2025}

The government of Tanzania has adopted a multi-sectoral approach to address poverty issues in the Development of Vision 2025 (TDV). This approach is adopted in order involve more stakeholders (sectors) its ensure sustainability [25]. The vision is to alleviate the existing poverty by improving socio-economic opportunities, good governance, transparency, and improved and redefined public sector performance, emphasizing also on appropriate balance between public and private institutions. Good governance of natural resource is featured in this vision. It is expected that by the year 2025 Tanzania will be a middle income country with reduced poverty and dependency. All these efforts are centered on resource utilizations be land, minerals, water, wild life and tourism just to mention a few.

\subsubsection{Tanzania Assistance Strategy (TAS)}

The TAS is a national medium-term framework for managing external resources and guiding development co-operation between the Government and its Development Partners. TAS aimed to promote national ownership and Government leadership of the development process and to enhance aid effectiveness through increased aid coordination, government leadership, strong ownership and dedication, harmonisation and involvement of stakeholders [7]. The strategy provides for improved management of external assistance and directing the same to the strategic intervention to enhance fast attainment of poverty reduction in the country [7, 25]. Since 2005, Tanzania as among the frontier economies has attracted foreign direct investment (FDI) from western multinationals and mining companies to invest in development sectors as seen in figure 1. These big companies invest in resources base to diversify the economy. The profit is transformed into infrastructures, water supply, education and medical care. These struggles have borne some fruits as maternity and infant mortality rate has significantly decreases over the past two decades. On the basis of such investment, the country is trying get rid from resource curse by achieving economic growth while diversifying away from the extractive sector. This reduces the country's economic vulnerability in case of the falls in resource prices and the depletion of reserves.

However, it is stipulated that external assistance will be received on hand while natural resources exploitations will be on the giving hand. It is the issue of policy and contracts which ensure that is the country which benefits and not few individuals through corruption. 


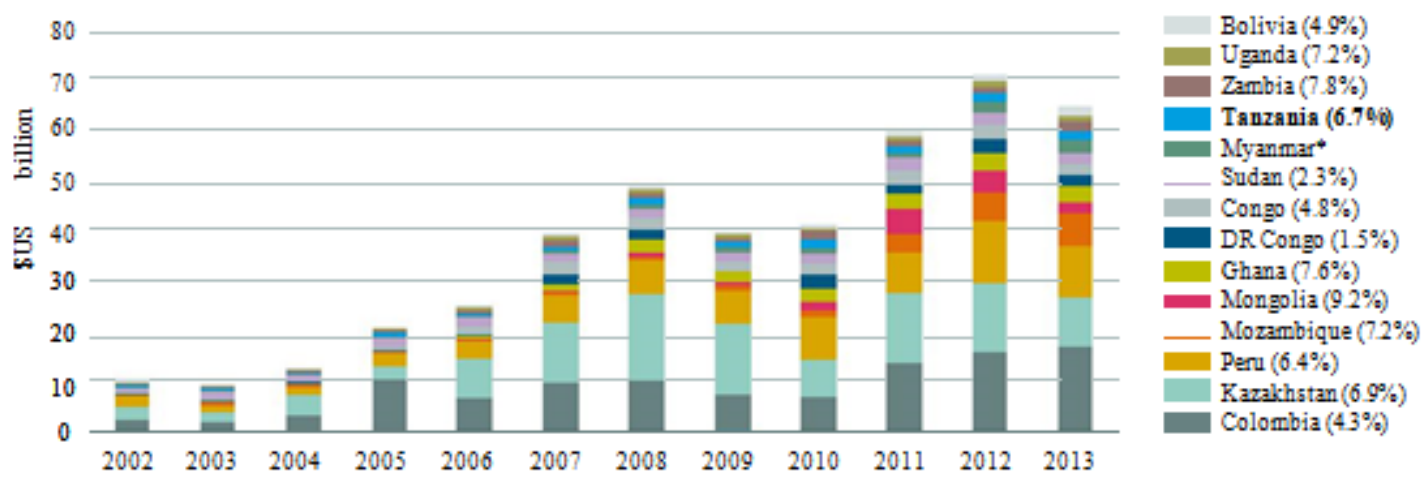

Sources: World Bank [26]

Figure 1. FDI net inflows (current US\$ billion) and GDP growth (\%) for 14 resource-driven economies

Figure 1 above Tanzania has a percentage growth of 6.7 GDP. This means, the level consumption, investment and government expenditure are insignificant to establish an economic stable country. And even the big share of investment is under foreign companies and firms. Under such a situation, the total gross national income (GNP) is less than the GDP. This is because the nation and her people have also not significantly invested outside the country. Despite of this FDI, the country's reliance on extractive sector is still massive.

\subsubsection{National Poverty Eradication Strategy}

National Strategy for Growth and Reduction of Poverty (NSGRP) is a strategy initiated to speeds up the reduction of poverty in Tanzania and was the result of The Poverty Reduction Strategy Paper of 2000, with a vision 2025 in 2005. This paper states that poverty is largely a rural phenomenon concentrated in the "subsistence farming sector, mostly in remote areas $[7,22,23]$. In this aspect, sustainable land management is the major engine to eradicating the poverty. In a country with more than $80 \%$ people involved in agriculture, proper strategies of land management need to be in place because land is their only accessible resource.

\subsection{Ways forward toward Poverty Alleviation in Tanzania}

\subsubsection{Participatory Approach}

Participatory approach should be done to involve local communities in planning and decision-making process [16, $17,18,19,20]$. For them to be key actors; they should be involved in the inception stage of any project thus identifying and addressing their livelihood priorities if when addressed they can progress in the socio-economic development [27]. Since the program is to reduce poverty, it is poor people who need to be more involved in the processes. If not involved, they may see that the program is not their belongings and therefore engage in the degradation of natural resources such as poaching and dynamite fishing [6, 25]. Avoidance of degradation of environmental resources will ensure resources sustainability.

\subsubsection{Policies and Regulations Should Be Harmonized}

Policies should be formulated in a practical way of considering the development of the poor in rural areas [27]. Rural livelihoods are mostly depending on the use of available natural. Therefore, planning should include them otherwise livelihoods option should be given to the people in order to reduce the reliance on natural resources $[12,13]$. Any possible development in other economic sectors such as industry will even reduce the reliance on natural resources and therefore reducing stresses over environmental resources.

\subsubsection{Review of Contracts with Investors}

The contracts signed with foreign investors on the natural resources management should be reviewed to rescue the country's foregoing wealth. Mining sectors, land, forestry, hunting permits and tourism are the major areas which need to be rescued for the betterment of the Tanzanian economy $[16,18,20]$. However, the review should be done in accordance to legal basis to avoid unnecessary cases and penalties. The review should focus at least ensure that government get the lion share of the royalty not like the current $3 \%$. This is the most important aspect because failure to do so, wrong doings will be legitimate.

\subsubsection{Increased Fighting against Corruption}

Corruption is the major setback toward sustainable utilization of natural resources and poverty alleviation. Corruption is spearheaded by weak governance as government official are deliberately bribed when signing government contracts with foreign investors. Therefore, the fighting against corruption should be strong with a clear anticipation to reduce it. Therefore, if corruption is reduced, there will be economic gains to the country and hence reducing poverty at national level. This can increase the gross domestic product and thus, we expect more consumption, investments and increases government spending's in the provision of social services. In addition, reduced corruption can improve natural resources than they used to be under corruption. This is because corrupt leaders forge permits over resources use to cause degradation and depletion. 


\subsubsection{Management of Natural Resources}

Natural resources should be well managed for sustainable development of both people and environment $[3,4,18]$. Despite of the participatory approach in natural resources management, expertise should be involved in the management. The people with competent knowledge on various resources base should be involved strongly in the planning, management and utilization of the resources and not relying on politics. This will help to reduce the mismanagement of natural resources like minerals, forest, wildlife and arable land, fisheries as well as marine and inland waters found in the country. This will reduce the existing degradation and depletion of natural resources. In addition, the neighboring communities to the national parks and game reserves should be effectively involved in the management of those resources to make them possess a sense of ownership. This will ensure sustainable management of resources.

\section{Conclusions}

Basing on the review, this paper reaches the following conclusion. Most developing countries are excelling in a pool of abject poverty despite of being endowed with natural resources. Tanzania is among these countries. The country has precious minerals, fertile land, inland drainage and national part to mention few but is among the poorest countries in the World. Despite of taking some measures of making natural resources utilization beneficial and sustainable for country development; these strategies have never been enough to reduce poverty. Among the main challenges includes; incorporating at present he environmental aspects in policy, regional and local planning, and budgets; making it an essential component of growth and development of the country. The country has a long way to go to meet sustainable socio-economic development of her people using available natural resources because of the fore mentioned challenges. It needs to control the prevailing problems in order to increase productivity.

This study therefore, suggests a win-win situation between resources exploitations and economic developments. The country should get rid from resource curse by achieving economic growth while diversifying away from the extractive sector. The diversification is very important because we mostly rely on non-renewable resources that can undergo depletion. To implement this, a more harmonized environments based on policies, human resources, technology and legal institution to make sure that natural resources have economic impacts to the poor especially in rural areas through the provision of good social services.

Meanwhile, a sustainable utilization of the available natural resources should be given a highest accord to avoid overutilization and depletion. A good example of getting rid from resource curse should be learned from Norway as she managed to develop oil deposit in North Sea in 1970. Norway had low corruption, good political systems and low population whom most were educated. She diversified the economy from dependency on crude oil. If all these are not done, the projection is that, the magnitude of the "resource curse" will be severe to devastate the poor's livelihoods.

\section{Acknowledgements}

The authors of this paper are thankful to all authors of the publications which they reviewed. In addition, they are indebted to anonymous reviewer for helpful comments and insights.

\section{Interest of Conflict}

No potential conflict of interest was reported by the authors.

\section{REFERENCES}

[1] Bagachwa M. (1994). Poverty Alleviation in Tanzania: Recent Research Issues, Dar-es-Salaam University Press, Dar-es-Salaam, Tanzania.

[2] IMF (1997) Annual Report of the Executive Board for the Financial Year Ended April 30, 1997

[3] Kader A. (2005). Increasing food availability by reducing postharvest losses of fresh produce. Acta Hortic. 682, 2169-2176.

[4] Krieger N (2001). Theories for social epidemiology in the 21st century: an eco-social perspective. Int J Epidemiol Aug; 30(4):668-77.

[5] Kulcsar L., Selfa T., Bain C. (2016). Privileged access and rural vulnerabilities: Examining social and environmental exploitation in bioenergy development in the American Midwest. Journal of Rural Studies

[6] Milledje S. et al (2007). Forestry, Governance and Natural Development: Lessons Learned from a Logging Boom in Southern Tanzania. An Overview. TRAFFIC East/Southern Africa/ Tanzania Development Partners Group/ Ministry of Natural Resources and Tourism, Dar-es-salaam, Tanzania. pg 16.

[7] MKUKUTA (2010). Monitoring System, Ministry of Finance and Economic Affairs. Dar- Es- Salaam. REPOA.

[8] Muganyizi, T. K. (2012). Mining Sector Taxation in Tanzania: ICTD Research

[9] Ravallion, M (1998). Poverty Line in Theory and Practice. Living Standard Measurement Study Working Paper No. 133. World Bank. Report 1. REPOA, Special Paper No. 06.19. Dar es Salaam: Mkuki na Nyota Publishers

[10] Robert, et al (2008) Sustaining and sharing economic growth in Tanzania, New York, Word Bank.

[11] Sen, A. (1983). Social Theory. Social Understanding, and political Action, In; Social Theory and Political Practice. New York, Oxford University Press. 
[12] Sen A. (1986). Food, Economics and Entitlements. WIDER Working Papers (1986-2000) 1986/001. Helsinki: UNU-WIDER.

[13] Steele O. et al. (2008). Poverty Reduction that works. New York, Earthscan.

[14] Stein J., Hong H (1999). A unified theory of underreaction, momentum trading and overreactions in assets market. The Journal of Finance. Vol. LIV. No. 6

[15] Stein H. (1990). Poverty, market, imperfections and time preferences: of relevance for environmental policy.

[16] URT (1997). Mineral Policy, Dar Es Salaam

[17] URT (1997). Agriculture and Livestock Policy, Dar Es Salaam

[18] URT (1997). National Environmental Policy, Dar Es Salaam

[19] URT (1998). National Forestry Policy, Dar Es Salaam

[20] URT (1999). National Tourism Policy, Dar Es Salaam
[21] URT (2002a). The Agricultural Sector Development Programme, the Agricultural Sector Lead Ministries, Dar es Salaam.

[22] URT (2004b). The Public Expenditure Review of Environment, Financial Year 2004. Final report 120 pages incl appendix.

[23] URT (2004c). SEA report of Tanzania Poverty Reduction Support Credit 2, Vice Presidents Office, Division of Environment.

[24] URT (2007). Wildlife Policy, Dar Es Salaam

[25] URT (2009). Poverty and Human Development Report "Research and Analysis working Group

[26] World Bank (2014). World Development Indicators, Washington.

[27] Wuyts M. (2006). Developing social protection in Tanzania within a context of generalized. 